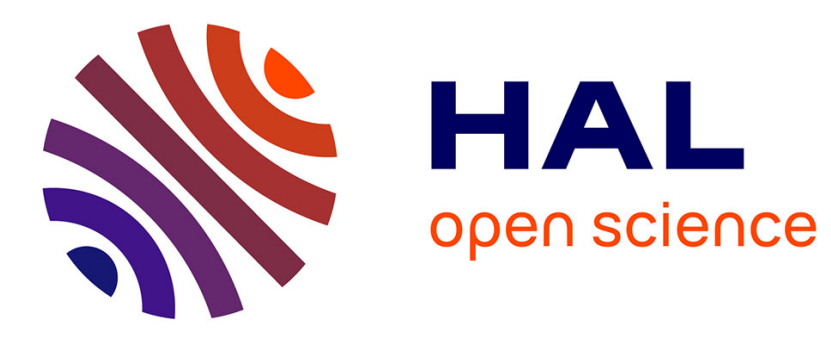

\title{
Augmenting the Textbook for Enaction: Designing Media for Participatory Learning in Classrooms
}

\author{
Priyanka Borar, Durgaprasad Karnam, Harshit Agrawal, Sanjay
}

Chandrasekharan

\section{- To cite this version:}

Priyanka Borar, Durgaprasad Karnam, Harshit Agrawal, Sanjay Chandrasekharan. Augmenting the Textbook for Enaction: Designing Media for Participatory Learning in Classrooms. 16th IFIP Conference on Human-Computer Interaction (INTERACT), Sep 2017, Bombay, India. pp.336-339, 10.1007/978-3-319-68059-0_24 . hal-01679790

\section{HAL Id: hal-01679790 \\ https://hal.inria.fr/hal-01679790}

Submitted on 10 Jan 2018

HAL is a multi-disciplinary open access archive for the deposit and dissemination of scientific research documents, whether they are published or not. The documents may come from teaching and research institutions in France or abroad, or from public or private research centers.
L'archive ouverte pluridisciplinaire HAL, est destinée au dépôt et à la diffusion de documents scientifiques de niveau recherche, publiés ou non, émanant des établissements d'enseignement et de recherche français ou étrangers, des laboratoires publics ou privés. 


\title{
Augmenting the Textbook for Enaction: Designing Media for Participatory Learning in Classrooms
}

\author{
Priyanka Borar ${ }^{1}$, Durga Prasad ${ }^{1}$, Harshit Agrawal ${ }^{1}$, and Sanjay Chandrasekharan ${ }^{2}$ \\ Homi Bhabha Centre for Science Education, TIFR, Mumbai \\ ${ }^{1}$ \{priyankaborar, karnamdpdurga, harshitagrawal.iitr\}@gmail.com \\ ${ }^{2}$ sanjayahbcse.tifr.res.in
}

\begin{abstract}
This work discusses the affordances of the textbook in current classroom scenarios, and identifies the need to design learning media that supports dynamism and enaction, specifically in science education. We illustrate this by a learning tool we've developed - Vector canvas, an AR based application linked with the textbook and the curricula. This is a work in progress attempting to observe and articulate changes in learning practice brought by introducing mixed media.
\end{abstract}

Keywords: AR, mixed media, dynamic systems, enaction, science education

\section{Introduction}

The current classroom environment relies heavily on print and paper media for teaching and learning practices. Through this case study we discuss the affordances of these media, its implications on science learning from a cognitive point of view, and its limitations in supporting dynamic nature of concepts and imagination. We present a case for the need to integrate enactable formal systems into the classroom practice that allow the learner to be 'immersed' in the formal systems, and help them enact, and thus become part of the dynamics embedded in formal notations.

The resulting participatory experience is intended to help the student move from the current algorithmic/procedural understanding of formal systems to a modelling perspective. We illustrate this by a learning tool - Vector canvas, designed to augment the physics class XI NCERT textbook to integrate the enactable nature of vectors through tasks designed based on the curricula.

The National Council of Educational Research and Training (NCERT) is an autonomous organisation set up in 1961 by the Government of India to assist and advise the Central and State Governments on policies and programmes for qualitative improvement in school education. 


\subsection{Agency in the Classroom}

Given the affordances of the print and writing media, the classroom practice is designed in a manner that the teacher enacts out concepts for the students explaining various physical phenomena by reading out laws, writing equations, sketching graphs and other diagrams on the board and, hold their attention. Students have at their disposal the pen and paper for note-taking and problem-solving. The classroom discourse is completely guided by the teacher and, the students are modelled as viewers. Experienced teachers are able to distribute agency and make the students participate in the classroom discourse.

The teacher uses language, diagramming and bodily gestures \& movement for enactment. As the complexity of the concepts increases, it becomes difficult for the teacher to draw multiple representations and suggest dynamics embedded in the concepts and, hence it becomes difficult for the student to hold the concepts in their imagination \& integrate these representations to make sense of the concepts. Once the teacher has enacted the concept, the only take-away for the student is the formula. Thus the student develops a tendency to have the formula as the starting point to engage with a problem, and the starting point for most teachers to initiate classroom discourse remains the textbook.

\subsection{Affordances of the Textbook}

The textbook as an artefact that involves the process of print and production, requires the design of the curricula to be modular, and the integration of modules is expected to be facilitated by the teacher in the classroom. This modularity could lead to some gaps in the concept flow. In our study, we started out by an extensive textbook analysis of the Class XII and XI physics and mathematics NCERT textbooks to map concept building on vectors and identifying gaps. To cite an example from our findings: vectors is first introduced in class XI as a part of the physics chapter on motion in a plane and then introduced only in class XII in mathematics.

A heavy dependency on the static media also leads to emphasising one method of working over another. For example, to quote the Physics class XII NCERT chapter 4 , $\operatorname{Pg} 71$, "Although the graphical method of adding vectors helps us in visualising the vectors and the resultant vector, it is sometimes tedious and has limited accuracy". This is a valid case of emphasising equation over geometry owing to the limitations of the medium, but we know that it's possible to work with accuracy in geometry, and integrate it with the equation, given the power of simulations and dynamic displays. 


\subsection{Emergence of Digital Learning Media}

Digital learning media has started appearing in educational landscape in the form of online platforms for learning \& educational games and, use of interactive boards and smart TVs in the classroom. We are interested in understanding what these media do to the teaching and learning practice, and what are the design considerations for shaping the learning behaviour through their use. For example, while online platforms like Khan Academy address the enaction of concepts by the teacher, digital apps like Touch Counts, GeoGebra and Graspable Math address the student enaction component. While these platforms can be incorporated by the teacher or the students as part of the classroom practice, most of them are not designed with a specific intention to be integrated as learning tools to support the classroom and the curricula, which leaves practitioners with the integration \& curation problem.

We propose a platform as an attempt to address these problems by use of mixed media in the classroom practice and a design approach that takes into consideration the flow \& interactions in a the classroom environment while hoping to leverage the agency of both the teacher and the learner.

\section{Vector Canvas: a Case in Augmenting the Textbook}

Vector canvas is a learning tool modelled as a digital slate to become part of the learning process. The objective of the tool is to make explicit the enactable nature of vectors through exploratory processes \& support imagination for dynamic behaviour.
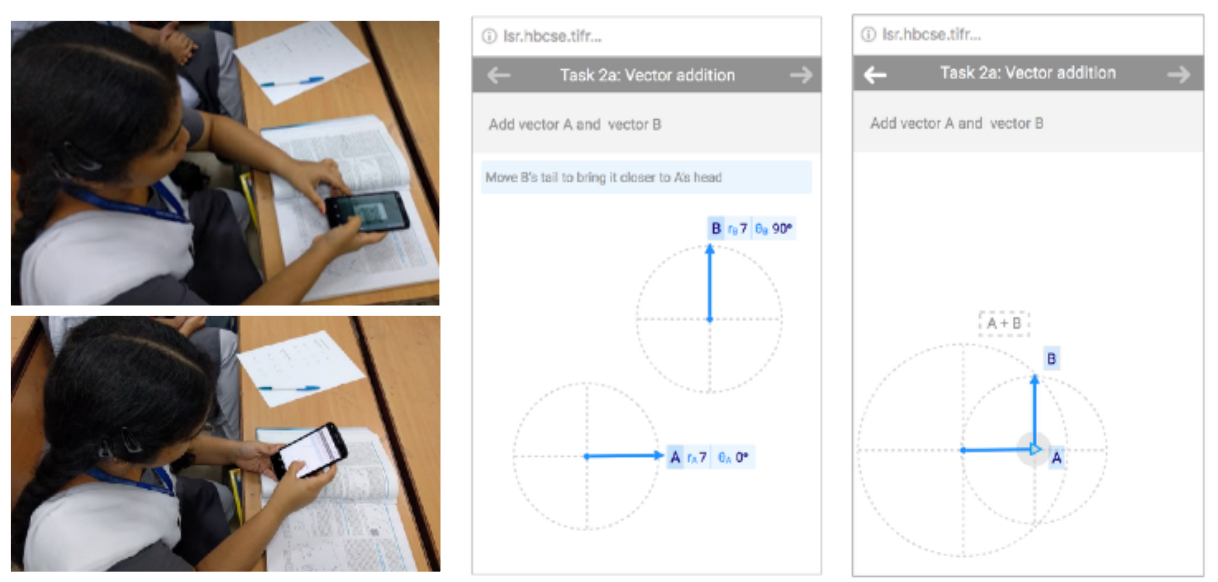

Fig. 1 A student performing the vector addition tasks and, task screens. 


\subsection{Design}

The starting point for the design of the platform was a simulation developed at the Learning Sciences research lab, HBCSE, that models vectors as dynamic and manipulable concepts and integrates them with equations. The simulation allows to touch and hold the vector on a digital display and manipulate it to change its length and angle. Operations like resolution and addition are also supported, while making explicit the dynamics involved in them. The challenge was to design learning experience for the classroom by developing media that integrates the power of the simulation to the existing practice.

An early prototype was inspired by a parallel work at the lab experimenting with augmented reality to tackle the problem of $3 \mathrm{D}$ representation in vectors in the textbook. Building from that platform and looking at available technologies that can be made accessible to masses, a new platform was proposed to use a mobile device in context of the lesson plan in the textbook by placing QR codes as markers within the lesson to trigger specific tasks designed from the simulation. Major design considerations and decisions are summarised below:

- Specific visual elements have been introduced to scaffold imagination such as axes for reference, a boundary circle to suggest the span of the vector and animations to emphasise the mechanism of vector operations such as addition and resolution.

- Manipulation is supported both by geometry and algebra i.e, by manipulating the vector as well as editing the equation. Both modes are synchronised, change through one immediately reflect in the other.

- Gestures for manipulation have been inspired by the use of geometry tools that emphasise intent in action vs. use of one-click commands to perform actions, for example using holding and taping to add vectors instead of using merge. While this increases learner's work, it also immerses her into the details of the concept.

- Tasks have been developed from the lesson plan and new exploratory tasks have been designed, for example, exploring all combinations of two vectors that give the same resultant by manipulating and adjusting given vectors.

\subsection{Future work}

This is a work in progress with some initial field testing and validation. While we develop it further, we are interested in learning and contributing to the design approach for learning media while focusing on how it changes the practice.

Acknowledgments. The above work is being realised at the Learning Sciences research lab at the HBCSE, Mumbai. We would like to thank all the teachers \& students participating in the research for their contributions. 